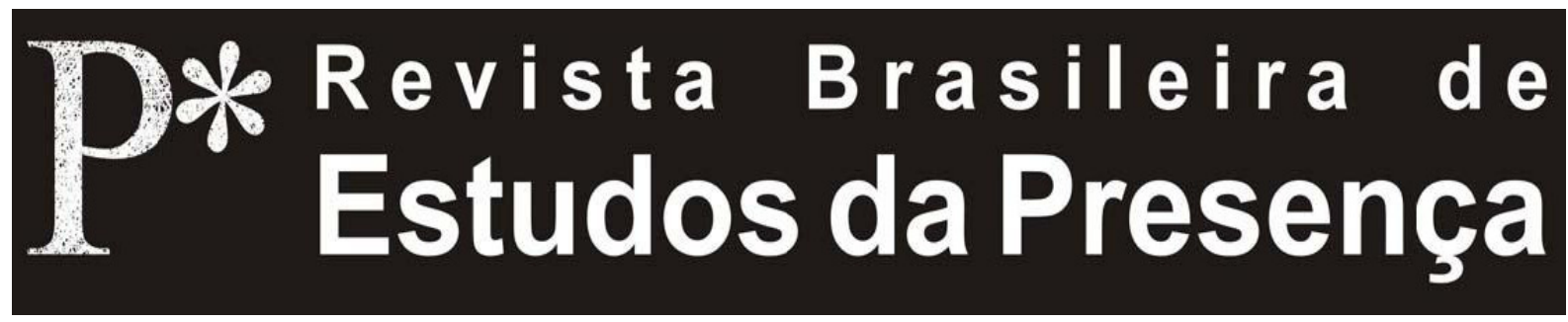

DOI - http://dx.doi.org/10.1590/2237-266031445

ISSN 2237-2660

\title{
"Contar histórias sempre foi a arte de contá-las de novo"
}

\author{
Ana Cecília de Carvalho Reckziegel \\ Gisela Costa Habeyche
}

Universidade Federal do Rio Grande do Sul - UFRGS, Porto Alegre, RS, Brasil

RESUMO - "Contar histórias sempre foi a arte de contá-las de novo" - O presente artigo discute alguns aspectos do processo improvisacional da criação do espetáculo Cinco tempos para a morte e os relaciona à experiência de presença descoberta nesse trabalho, a partir do pensamento de Richard Schechner, Henri Bergson e Walter Benjamin. Para tanto são pinçadas duas cenas performadas pelas próprias autoras na montagem mencionada, que consistem na narração de dois acontecimentos vividos pelas atrizes, colocando-as na situação de realizar um depoimento diante da plateia, sem a intermediação de um personagem.

Palavras-chave: Processo de Criação. Improvisação. Experiência. Usina do Trabalho do Ator. Cinco Tempos para a Morte.

ABSTRACT - "Telling stories has always been the art of telling them again" - This article discusses a few points of the improvisational process during the creation of the play Cinco tempos para a morte relating them to experiences of presence found during the process, based on the writings of Richard Schechner, Henri Bergson and Walter Benjamin. In order to do so, we chose two scenes performed by the authors of the play themselves in which they talk about two events from their own lives, putting them in the position to offer the audience real testimonies without the intermediation of a character.

Keywords: Creative Process. Improvisation. Experience. Usina do Trabalho do Ator. Cinco Tempos para a Morte.

RÉSUMÉ - “Conter des histoires a toujours été l'art de les reconter" - Cet article analyse certains aspects du processus improvisationnel de la création du spectacle Cinco tempos para a morte tout en les associant à l'expérience de la présence observée dans ce travail, à la lueur de la pensée de Richard Schechner, Henri Bergson et Walter Benjamin. Pour ce faire, deux scènes jouées par les auteures elles-mêmes dans le montage cité ci-dessus ont été choisies. Elles consistent à raconter deux faits vécus par les actrices, leur permettant de réaliser un témoignage face au public, sans l'intervention d'un personnage.

Mots-clés: Processus de Création. Improvisation. Expérience. Usina do Trabalho do Ator. Cinco Tempos para a Morte. 
Representar significa "[...] nunca pela primeira vez. Isso significa: da segunda até $n$ vezes. A representação é o "comportamento repetido" (Schechner, 1995, p. 206). O comportamento repetido é, para Schechner, o comportamento restaurado, compreendido como "[...] o comportamento vivo tratado como um diretor de filme trata uma fita cinematográfica. Essas sequências de comportamento podem ser rearranjadas ou reconstruídas; elas são independentes dos sistemas causais (social, psicológico, tecnológico) que os trouxeram à existência" $(1995$, p. 203). Capacitar-se para executar esse comportamento, que será repetido $n$ vezes, é um dos principais objetivos do ator do Núcleo de Investigação Usina do Trabalho do Ator (UTA), tanto em seu processo de formação, como nos processos de criação de seus espetáculos.

Criado em 1992, o UTA - grupo em que atuamos como pesquisadoras e atrizes - tem como principal objetivo a investigação prática do trabalho do ator. As técnicas investigadas, retrabalhadas e reconstruídas a partir da ótica do grupo, são experimentadas através da criação de espetáculos. Há, portanto, um primeiro momento direcionado ao estudo das técnicas, e um segundo momento, quando as técnicas já estão incorporadas pelos atores, no qual as mesmas são as ferramentas para o trabalho criativo. Ao longo dos anos a improvisação é o principal método utilizado pelo UTA nos processos de criação de seus espetáculos. Neste artigo pretendemos refletir sobre o processo improvisacional utilizado na montagem do espetáculo Cinco tempos para a morte, e sobre a experiência de presença que flagramos nesse trabalho, a partir do pensamento de Richard Schechner, Henri Bergson e Walter Benjamin.

Compreendemos o processo improvisacional como "[...] um caminho livre no qual o ator atinge seu inconsciente, mergulha no seu eu, como fonte de toda criação dramática possível" (Icle, 2002, p. 76). É nele que o ator do UTA exercita plenamente suas potencialidades técnicas e criativas, sem perseguir resultados imediatos e utilizar situações ou ideias pré-estabelecidas que lhe deem segurança, mas, ao contrário, permitindo-se entrar em terreno desconhecido. A improvisação é o caminho que possibilita ao ator pensar criativamente, conforme nos diz Barba: "[...] o pensamento criativo se dis- 
tingue justamente por prosseguir em saltos, por meio de uma desorientação inesperada que o obriga a se reorganizar de novas maneiras [...]" (Barba, 1995, p. 58).

Mas, como se dá o processo improvisacional no âmbito do trabalho do UTA? Como ele pode gerar um espetáculo teatral? Essas duas questões, para nós atores, parecem desnecessárias, uma vez que o método improvisacional é largamente utilizado, tanto para estudos de formação de atores e estudos de técnicas de atuação, como para a criação de personagens e espetáculos. No entanto, Schechner aponta que o ofício do ator é repetir o espetáculo criado, tantas vezes quantas sejam necessárias, através da restauração de um comportamento, o que, no caso do UTA e de sua própria concepção, surgiu no momento de uma improvisação. A cada vez que repetimos o mesmo espetáculo é nosso desejo atingir a qualidade da experiência que vivenciamos quando realizamos pela primeira vez as improvisações que, retrabalhadas, compõem o espetáculo.

\section{A Improvisação Teatral como Processo de Criação}

A utilização da improvisação teatral, como processo de criação de espetáculos pelo UTA, apresenta dois momentos básicos: a criação da cena por intermédio de uma improvisação e a recuperação e fixação dessa cena, dando-lhe a forma necessária para tornar-se um espetáculo. Nesse segundo momento, o trabalho de recuperação da cena ocorre pela repetição da mesma, com o objetivo de fixá-la em uma partitura de ações e, finalmente, com o entrelaçamento de diferentes partituras, efetuar a montagem do espetáculo. Nessa fase do trabalho, durante os ensaios, busca-se reconstituir a vitalidade daquele que podemos chamar de momento do nascimento da cena, quando realizamos pela primeira vez uma improvisação que se desenvolveu a contento, a qual denominamos improvisação matriz.

Muitas vezes, quando improvisamos pela primeira vez sobre um determinado tema ou situação, a cena vai se construindo durante o próprio processo da improvisação e tão perfeitamente que não podemos pensá-la de outra forma. Essa 
vivência dá ao ator uma sensação que, por mais que tentemos, é muito difícil de descrever por meio de palavras. Sua intensidade é tamanha que nos provoca, ao mesmo tempo, uma sensação onírica e um sentimento de concretude, no sentido de algo imaterial que se manifesta tão fortemente que pode ser transformado em ação.

Essa sensação, fruto do estado psicofísico para o qual o ator se transporta e é transportado durante a vivência improvisacional, e que dá à cena gerada uma qualidade única, nos leva a compreender a improvisação não somente como uma ferramenta para a construção de cenas, mas também como o processo em que o ator torna-se sua própria fonte de criação. Essa compreensão da improvisação é alargada pela noção de intuição de Bergson (2006), que nos auxilia a compreender a sensação desse algo de imaterial que se manifesta de forma tão marcante, especialmente quando pensamos que durante o processo de criação o ator trabalha intuitivamente, com essa consciência imediata e alargada, com essa visão que mal se distingue do objeto, que é o próprio ator - seu corpo, voz e mente.

\begin{abstract}
A intuição de que falamos [...] versa antes de tudo sobre a duração interior. Apreende uma sucessão que não é justaposição, um crescimento por dentro, o prolongamento ininterrupto do passado num presente que avança sobre o porvir. É a visão direta do espírito sobre o espírito. Nada mais de interposto, nada de refração através do prisma do qual uma das faces é espaço e a outra é linguagem. Ao invés de estados contíguos a estados, que se tornarão palavras justapostas a palavras, eis a continuidade do indizível e, por isso mesmo, substancial do fluxo da vida interior. Intuição, portanto, significa primeiro consciência, mas consciência imediata, visão que mal se distingue do objeto, conhecimento que é contato e mesmo coincidência. É, em segundo lugar, consciência alargada, premendo contra os bordos de um inconsciente que cede e que resiste, que se rende e que se retoma: através de alternâncias rápidas de obscuridade e de luz, faz-nos constatar que o inconsciente está aí; contra a estrita lógica, afirma que por mais que o psicológico seja algo inconsciente, há não obstante um inconsciente psicológico (Bergson, 2006, p. 29-30).
\end{abstract}


O segundo momento do trabalho do ator, no processo de criação de espetáculo do UTA, é o momento da recuperação e fixação da cena improvisada. Isso se dá nos ensaios, durante os quais o ator faz suas escolhas e vai organizando suas sequências de ações. Os ensaios "[...] funcionam para construir uma partitura, e essa partitura é um 'ritual por contrato': um comportamento pré-fixado que cada participante concorda em fazer" (Schechner, 1995, p. 206). A cada ensaio e, posteriormente, a cada apresentação do espetáculo, o ator entra novamente em contato com essas partituras, essas "[...] sequências de comportamento, recuperam-nas, lhes dão novamente vida e até as inventam, e, então, se recomportando de acordo com essas sequências [...]"' (Schechner, 1995, p. 205-206).

Esse segundo momento é de elaboração de um processo interior, que em determinada circunstância solicita a mediação da razão entre o ator e seu objeto artístico (ele mesmo e sua partitura de ações). É o momento de repetir, de selecionar, de ordenar. $\mathrm{O}$ ator trabalha aqui com suas ferramentas técnicas, as quais, como bem diz Bergson, precisa conhecer e sobre as quais deve saber tudo o que lhe seja possível. A técnica que

[...] é comandada pelas exigências da matéria sobre a qual ele opera e que se impõe a ele como a todos os artistas; remete, na arte, àquilo que é repetição ou fabricação, e não mais a própria criação. Sobre ela se concentra a atenção do artista, o que eu chamaria sua intelectualidade (2006, p. 107).

Quando retomamos a improvisação para estudá-la e tentarmos repeti-la é realmente como se tomássemos aquele fragmento de tempo e o picotássemos, tal qual os frames de um filme. É como se buscássemos reproduzir com o corpo os fragmentos de tempo, quadro a quadro, como se esculpíssemos estátuas vivas para perceber onde começa e termina cada ação, como e de que maneira se relaciona com outro ator, em que ponto do espaço e em que velocidade. Então, trata-se realmente da transformação do tempo, daquilo que fluiu, em espaço. No entanto, nosso corpo, nossa matéria, não perde a qualidade do momento em que a improvisação se fez, há um constante entrar e sair daquele estado. E, obviamente, quando 
voltar a repeti-la, depois de decupada e memorizada, o ator buscará relacionar-se com sua partitura por intermédio da intuição para torná-la fluxo novamente.

Costumamos afirmar que o ator é, a um só tempo, criador e criatura. Encontramos em Bergson esse olhar, de uma relação profunda e sensível, entre um mundo externo e um mundo interno, que estão contidos um no outro: “[...] a matéria e a vida que preenchem o mundo estão igualmente em nós; as forças que trabalham em todas as coisas, sentimo-las em nós; seja lá qual for a essência íntima daquilo que é e daquilo que se faz, somos parte disso [...]" (Bergson, 2006, p. 143). E acrescentaríamos: aquilo que é e que se faz é parte de nós. Então, podemos pensar que, quanto mais profundo for o contato do ator com a realidade ficcional, mais forte será o ímpeto que essa devolverá a ele na superfície. Podemos pensar que a intuição artística é esse contato, e, na medida em que o ator experienciar esse contato, poderá ser capaz de tocar o espectador.

\section{Outros Modos de Atuar}

O processo de criação do espetáculo teatral Cinco tempos para a morte, doravante também nomeado Cinco tempos, inaugurou algumas experiências para os integrantes da Usina do Trabalho do Ator (UTA).

O que experienciamos nesse fazer, que ocorreu às vésperas dos vinte anos do grupo - momento particularmente convidativo para tecer reflexões -, nos levou a investigar um novo jeito de fazer teatro (novo em relação a nossa trajetória) e, nessa trilha, nos desacomodamos especialmente acerca da maneira como ocupar a cena, buscando certo tipo de presença, perturbados por uma nova compreensão de atuação que descobríamos emergir na nossa prática e ainda nos desafia, pois se estabelece como ausência, nos obriga a um esvaziamento.

Essa indagação de uma presença que se estabelece como ausência, na desconstrução do que nós supúnhamos conhecer, oportuniza um tipo de comunicação especial com o público, uma troca que pode ajudar o espectador a acessar suas vivências em relação à morte, temática fundante de Cinco Tempos. 
Algo que caracteriza a maneira de conceber os trabalhos no UTA, e que ocorre também em Cinco Tempos, é o fato de não partimos de textos dramáticos para criar, mas o fazermos por improvisações a partir de um tema escolhido - neste caso, a morte. Esse percurso gera, ao fim, um texto e, além dele, cria também o investimento em cenas que se resolvem pelas ações, pela visualidade, pela música, pela relação estabelecida entre os atores, enfim, diversifica os elementos deflagradores/condutores da cena, que não se restringem ao texto propriamente dito. Tal caminho oferece, por certo, um espectro diversificado a cada nova investida, mas, ainda assim, existem trilhas habituais na maneira de encaminhar e desenvolver as proposições e outras que são originais para quem não as vivenciou, sendo, nesse sentido, inaugurais.

No projeto em questão, houve a saída de Gilberto Icle da atuação, para que ele se concentrasse na direção do trabalho, que contou também com a assistência de direção de Shirley Rosário, nova integrante na equipe.

Os ensaios começaram em abril de 2010, com improvisações que inicialmente consistiam em tarefas pontuais propostas por Gilberto Icle, relacionadas a formas de nos envolvermos com o tema e uns com os outros ao ocuparmos a cena. Aos poucos, os atores foram trazendo mais e mais sugestões, criando situações e figuras, oferecendo materiais passíveis de criar uma dramaturgia, ainda sem a preocupação de criar cenas, nem mesmo da pertinência do que fazíamos. Levamos para nosso espaço de ensaio muitos objetos que permitiram que nos caracterizássemos diferentemente para cada proposta surgida, dando vazão àquilo que imaginávamos e que nos ajudava a sair de nós mesmos, a abrir-nos para instaurar outras figuras e comportamentos pela relação com os objetos.

Inventamos atividades que funcionavam como um jeito de obter o que nos parecia um bom estado de entrar no trabalho, um estado no qual o corpo está alongado e quente, a concentração é precisa e a atenção é plena. Um estado no qual o que quer que aconteça deflagra outro acontecimento.

Um dos nossos jogos favoritos começava com a execução, pelo grupo todo, ao mesmo tempo, de um movimento qualquer 
e, a cada vez que se mudava a direção no espaço, a condução da movimentação era feita por outro colega, sem interrupções e com grande entrega. Depois de algumas vezes jogando assim, conseguíamos contar histórias inteiras, algumas vezes com a existência concomitante de um coro que reagia ou propunha, e de figuras que se destacavam do coletivo e desenvolviam ações próprias. Como o movimento é o trampolim para esse jogo, ocorre uma minimização de qualquer pensamento ou racionalização que possa advir, viabilizando o deixar acontecer, o soltar o comando e seguir o fluxo da proposta.

Para além do importante treinamento de diversas habilidades que visam a disponibilidade e fluência dos atores, entre outras qualidades que podemos encapsular sob o amplo nome de presença, nos demos conta de que procuramos também desenvolver outras linguagens, diferentes maneiras de estabelecer o encontro com o público. Tais compartilhamentos intermediados por um espetáculo, e estabelecidos na copresença de atores e plateia, renovam nossa crença no valor de recontar histórias e no poder desse gesto, matriz de experiências.

De fato, o desejo de encontro através do fazer teatral nos conduz ao pensamento de Walter Benjamin sobre experiência.

O tédio é o pássaro de sonho que choca os ovos da experiência. O menor sussurro nas folhagens o assusta. Seus ninhos - as atividades intimamente associadas ao tédio - já se extinguiram na cidade e estão em vias de extinção no campo. Com isso, desaparece o dom de ouvir e desaparece a comunidade dos ouvintes. Contar histórias sempre foi a arte de contá-las de novo, e ela se perde quando as histórias não são mais conservadas. [...] Quanto mais o ouvinte se esquece de si mesmo, mais profundamente se grava nele o que é ouvido. Quando o ritmo do trabalho se apodera dele, ele escuta as histórias de tal maneira que adquire espontaneamente o dom de narrá-las. Assim se teceu a rede em que está guardado o dom narrativo (Benjamin, 1993, p. 204-205).

A imagem de um pássaro de sonho, assustado, chocando os ovos da experiência no ninho da escuta, no lugar do estabelecimento de um contato que se repete enquanto repetidas vezes são contadas as histórias; a imagem dessa rede na qual está guardado o poder narrativo, que se tece como uma ha- 
bilidade que vai se desenvolvendo pelo fazer e repetir e que levará ao lugar que antes era ocupado pelo outro, de assumir a narração e reconduzir a escuta - essas imagens remetem à vida que pulsa em algo de fundamental que faz os seres humanos capazes de agirem juntos para criarem o que só se estabelece nessa reunião. Quando se pensa nos efeitos da arte da narração eles, inevitavelmente, remetem ao encontro e à transformação dos participantes do evento, que se percebe serem da mesma natureza do que acontece na criação teatral; ambos têm um feitio de experiência.

Se acolhermos experiência em consonância com o convite de Walter Benjamin (1993), como algo que pode ser transmitido e, portanto, criador da capacidade de reconectar as pessoas, o mais recente trabalho do UTA procura rearticular alguns meios de cumprir tal função reconectora.

Desejamos com essa proposta ir ao encontro do reinado da pobreza das experiências comunicáveis, como apontado por Walter Benjamin (1993). Assim, retomamos a arte de narrar e a "faculdade de intercambiar experiências" (Benjamin, 1993, p. 198) que ela mantém viva.

O espetáculo Cinco tempos para a morte foi organizado como uma colagem de cenas variadas e resultou não linear, entrecortado, com nuances de tons, capaz de oferecer diferentes níveis de atuação, desde interpretações mais realistas, com personagens propriamente ditos, a situações mais herméticas, simbólicas, algumas das quais levam o próprio fazer teatral para a cena e, também, outras nas quais os atores mesmos realizam depoimentos pinçados de suas vidas. Além de apresentar muitas imagens de morte, também o teatro foi referenciado em Cinco Tempos.

Somos cinco atores jogando diversos papéis, inclusive nós mesmos em cena. Trata-se de um espetáculo que tem uma estrutura fragmentada, apresentando algumas situações que retornam e cenas que não necessariamente têm relação umas com as outras, no sentido de nem sempre terem continuidade. $\mathrm{O}$ acolhimento da fragmentação nos ofereceu descontinuidades não apenas acerca das histórias contadas em si, mas também numa certa liberdade de pensar nossas ações, como perten- 
centes a universos distintos umas das outras, sem a responsabilidade de uma unidade coerente de atuação. Tal liberdade contribuiu para que pesquisássemos outras possibilidades de jogar, das quais pinçamos uma das maneiras de ocupar a cena, que parece pertinente para refletir sobre a presença como experiência em teatro.

Trata-se do que chamamos de depoimentos. São diferentes momentos do espetáculo em que cada um dos cinco atores narra um acontecimento particular da própria vida. Traçamos a presente reflexão com o foco nos depoimentos das duas autoras, que são atrizes do UTA.

Consideramos que as figuras que apresentamos na criação de Cinco Tempos revelam nós mesmas, ao experienciar a situação de realizar um depoimento.

Uma dessas situações apresenta uma das autoras contando um sonho que teve com seu avô, após a sua morte. Ela relata o sonho, no qual ela estava num dos grandes e festivos almoços celebrados em Florianópolis, que reuniam toda a sua família. Em determinado momento, em que foi à cozinha e passou pela peça que era o escritório do seu avô, encontrou-o sentado e perguntou-lhe o que estava fazendo ali. Como resposta ele lhe explicava que morrer era muito bom, mas que tinha muita saudade da comida da Terra e então pedia que ela lhe fizesse um favor: que fosse à cozinha e lhe preparasse um prato de comida, com um bom bife à milanesa.

Diversas vezes ouvimos referências espontâneas acerca desse depoimento. Algumas mencionavam a estranheza de ouvir o avô mencionar saudade da comida da Terra, como se pairasse sob essa escolha uma tendência espiritualista, que não parecia estar de acordo com o tom do espetáculo. Se alguém do público faz menção a certo tom do espetáculo é possível considerar que existe aí a criação de uma unidade de leitura para o trabalho; alguém que se ocupou de juntar as peças do quebra-cabeça que oferecemos e converteu informações entrecortadas e disjuntas em algo que apresenta uma coerência, um plano coeso que oferece certo tom.

Outras vezes, o que escutamos sobre esse depoimento denotava uma espécie de espelhamento ou identificação, pois 
algumas pessoas afirmavam que um bom bife à milanesa era de fato uma comida digna de se ter saudade após a morte. $\mathrm{O}$ compartilhamento desse pensamento nos leva a entender que pelo menos alguém - de alguma das plateias de Cinco tempos - fez um movimento de considerar a hipótese da própria morte e de acompanhar, hipoteticamente, o desejo de comer algo que lhe agradasse após a morte. Se tal movimento ocorreu, podese pensar num gesto de captura de algo na presença do ator para olhar a si mesmo, ainda que por um instante. Podemos crer que esse gesto é da ordem da experiência: alguém narra algo que permite uma aproximação, um voltar a si promovido a partir da ação do outro, uma troca, um compartilhamento.

Outra de nós conta uma história sobre seu pai, cuja perda lhe provocou a pensar a morte como tema para o trabalho e que, proposta aos parceiros do grupo, foi acolhida para a realização do espetáculo.

Especificamente nesse contar, a atriz revela algo que a constitui há muito tempo, por observar seu pai vivenciando situações de perdas, assim como de tê-lo ouvido contar as razões desse seu estranho procedimento. Em termos de atuação teatral, por mais paradoxal que seja, parece que não há atuação propriamente dita, pois é de um lugar de não distanciamento de si mesma que o conta, mantendo o envolvimento pessoal, deixando vivas suas emoções em relação ao que narra, o que permite antever sua dor diante da perda, assim como a construção da aceitação de tê-lo perdido. No entanto, há uma elaboração diferenciada nesse modo de estar presente. Tal elaboração poderia ser associada, em ambas as cenas descritas, à procura de uma ausência de interpretação, o que nos remeteria ao entendimento de outra faceta de presença permeando o trabalho, relacionada à ausência.

Em uma anotação do seu diário de trabalho, do dia 23 de abril de 2010, há o registro de que “[...] existe algo novo nesse trabalho relativo a não interpretar. Como se o que interessasse não fosse do terreno da ficção e sim das verdades e experiências vividas por nós. Menos a ideia de inventar e mais a de compartilhar" (Habeyche, 2010, p. 23).

João Pedro Alcântara Gil, no seu Fragmentos de um teatro amoroso (2010), sinaliza que "[...] o teatro não mais expõe 
situações, mas presentifica a fábula como um inventário de acontecimentos particulares". E, "[...] portanto, segue uma tendência da pesquisa contemporânea em educação e arte que é investigar trajetórias interessantes de artistas e professores" (2010, p. 115).

Ao seguir, então, essa tendência contemporânea, o depoimento que realiza, como referia, concebe uma espécie de entrega diferente, uma qualidade especial de troca humana que materializa no teatro com sua presença real e material. Luís Otávio Burnier contribui com a discussão quando diz que "[...] todo intérprete é um intermediário, alguém que está no entre. No caso do teatro, ele está entre o personagem e o espectador, portanto entre algo que é ficção e alguém real e material" (2001, p. 22).

Mas, como podemos ser intermediárias quando não existe um personagem? Trazer para a cena um fato vivenciado torna-o ficcional, ou nos torna parte da ficção? Os estudos de Burnier revelam-se ainda mais generosos quando se referem a determinados modos de pensar a arte de ator que se expressam em como nomeamos o que o ator faz.

Em seu sentido próprio, interpretar quer dizer traduzir,
e representar significa 'estar no lugar de' (o chefe de
gabinete que representa o prefeito), mas também pode
significar o encontro de um equivalente. Assim, quando
um ator interpreta um personagem, ele está realizando
a tradução de uma linguagem literária para a cênica;
quando ele representa, está encontrando um equivalente
(Burnier, 2001, p. 21).

O que criamos, com nossos depoimentos, seria, então, o equivalente a representar um personagem? $\mathrm{O}$ equivalente de uma atuação?

Poderíamos levar essa discussão um pouco mais adiante se considerarmos o modo como os atores do Théâtre du Soleil, dirigidos por Ariane Mnouchkine, pensam a sua criação. Segundo Paulo Vieira,

Ariane parte do princípio de que o ator é um receptáculo ativo, que deve, ao mesmo tempo, ser côncavo e convexo. Côncavo para receber, convexo para projetar. 
Entrar para a cena significa entrar num lugar simbólico, onde tudo é musical e poético. [...] Talvez não seja exagerado lembrar que o teatro é algo que possui a sua própria verdade, e que esta não é a mesma da realidade. Esse vem a ser o motivo pelo qual Ariane, durante o jogo de preparação do ator, toma uma direção contrária a que Stanislavski apontou, trabalhando antes as situações propostas do que as emoções que são, a seu ver, o resultado do encontro entre o ator e o espectador. Esse encontro [...] se dá pela intermediação do jogo, não da representação, pois 'representar' é uma forma não verossímil de intermediar aquilo que há no mundo imaginário do palco. [...] faz-se necessário mudar a relação do ator com o personagem, quando, então, o ator deve passar do plano da 'representação' para o plano do jogo (Féral, 2010, p. 18-19).

Tal maneira de nomear o trabalho do ator nos aproxima do modo como criamos no UTA, compartilhando o jogo com os espectadores, auxiliando a compreender o depoimento como algo que talvez não se inscreva como ficção, mas que é oferecido ao ser contado. Talvez isso esteja ainda mais próximo do narrador de Benjamin (1993), que mescla suas próprias experiências àquilo que narra. Afinal, nesses depoimentos compartilhamos, em breves instantes, algo que fez parte de nossas vidas e que, de alguma forma, demonstra o estado de vulnerabilidade em face da morte de alguém amado.

É claro que estabelecemos um texto, trabalhamos a precisão articulatória desse texto que dizemos, assim como criamos uma partitura rítmica aproximada do que realizamos, mas procuramos a nossa energia para estar em cena, buscamos um falar próximo do nosso cotidiano, a conexão com os sentimentos e com o momento presente. É como se dividíssemos algo absolutamente pessoal e íntimo com o público.

No entanto, seria inocente não duvidar dessa impressão de não atuação, tendo em vista que se trata de uma parte de um espetáculo no qual existe um público para quem aparecemos como atrizes, cujo papel esperado é o de atuar. Inclusive porque podemos aproveitar essa fronteira surgida para não tomar como dado o que, afinal, é estar em cena ou atuar, ou o que seja o trabalho do ator, posto que essa interrogação pode servir para levar adiante nossas investigações. Reconhecemos 
ainda um desejo de contato pelo simples fato de contar o que contamos para nossos interlocutores. O que seria criado com a ação deliberadamente dirigida aos outros, caso não se tratasse de atuação teatral?

Desconfiamos de que esse momento do espetáculo propicia uma experiência. Não apenas em relação ao que foi vivenciado com o pai e o avô, mas por termos ouvido referências a esses momentos de alguns espectadores. Mencionamos falas espontâneas, recebidas aqui e ali, ocasionalmente, e sem outro registro senão a memória. Essas falas vieram de diferentes pessoas, desde algumas que nunca tínhamos visto, até outras que nos conheciam bem.

As colocações que ouvimos relativas a essas cenas são da ordem do: se é verdade ou não isso que contamos na totalidade das vezes. Algumas referem a emoção que sentem ao ouvila e/ou como a imagem continua os acompanhando mesmo depois da apresentação do espetáculo. Outras manifestam o exercício realizado como espectador, de se perguntar, se ele fosse compartilhar algo da sua vida relacionado com a morte, o que seria. Estes últimos, com efeito, nos fazem suspeitar de uma dimensão política na experiência teatral.

O texto que uma nós diz é o seguinte:

\begin{abstract}
Meu pai era muito impressionado com a história do Caronte: o barqueiro do rio das Almas, que fazia o transporte de quem tinha morrido, do mundo dos vivos para o mundo dos mortos, mediante o pagamento de uma moeda. Então, cada vez que ele perdia alguém de quem ele gostava muito ele dava um jeito, discretamente, de colocar uma moeda no caixão da pessoa, que era pra ela poder fazer a travessia; mas só os amigos mais chegados a ele é que sabiam disso. Quando meu pai morreu eu fui colocar uma moeda no bolso do seu paletó, e quando eu cheguei com a moeda o bolso já tava cheio, cheinho de moedas (Habeyche, 2010, p. 41).
\end{abstract}

Para compartilhar essas histórias como o fizemos, de maneira econômica e sem a proteção de um personagem, ou qualquer estado ficcional constituído diferentemente de nós mesmas, houve uma longa caminhada de interrogação de nossa compreensão de teatralidade. Nesse sentido, é como se 
nos ausentássemos da nossa condição de atrizes para realizar os depoimentos, ou precisássemos encontrar em nós um esvaziamento de como acreditávamos que era possível constituir um estado cênico. Nesse caso, a ausência é também de nossa idealização do jogo do ator e envolve uma desconstrução de nós mesmas, daquilo que acreditávamos, de quaisquer fórmulas de presença imaginadas antes do processo criativo de Cinco Tempos.

O crítico cultural e catedrático de história Martin Jay, no seu Cantos de experiencia: variaciones modernas sobre un tema universal, aborda incontáveis acepções de experiência que se descortinam como possíveis para pensar tanto questões advindas da ordem prática, como da teorização, em áreas tão ímpares como religião, estética, política, história, epistemologia, em diálogo com a filosofia. Ele assevera que experiência é "[...] um significante suscetível de desencadear profundas emoções em quem o confie a um lugar de privilégio em seu pensamento" (2009, p. 15-16). Jay afirma que "[...] não por nada os pensadores de outras tradições culturais puderam falar também de um 'culto', 'mito', 'idolatria' ou 'misticismo' da experiência, tão poderoso tem sido seu atrativo" (2009, p. 16).

Mas, no que pese esse poder de atração, Jay não se convence com nenhuma das alternativas que expõe, crê ser mais frutífero permanecer na tensão criada pelo paradoxo de que a experiência "[...] se acha no ponto nodal da intersecção entre a linguagem pública e a subjetividade privada, entre os rasgos comuns expressáveis e o caráter inefável da interioridade individual" (Jay, 2009, p. 20).

É precisamente nesse mesmo ponto de intersecção que se insere essa reflexão, entre um tipo de experiência que nos é particular e mesmo íntima, ao pesquisar sobre nossos aprendizados como atrizes, e esse fazer coletivo, que se relaciona à criação de um espetáculo teatral determinado, o que envolve não apenas o grupo de teatro que vivencia esse processo, $o$ UTA, mas um público, diferente a cada noite, com quem compartilhamos a experiência do teatro em si. 


\section{Referências}

BARBA, Eugenio; SAVARESI, Nicola. A Arte Secreta do Ator. São Paulo-Campinas: Editora Hucitec/ Editora da UNICAMP, 1995.

BENJAMIN, Walter. O Narrador. In: BENJAMIN, Walter. Magia e Técnica, Arte e Política: ensaios sobre literatura e história da cultura. Tradução de Sergio Paulo Rouanet. São Paulo: Brasiliense, 1993. P. 197-221.

BERGSON, Henri. O Pensamento e o Movente. São Paulo: Martins Fontes, 2006.

BURNIER, Luis Otávio. A Arte de Ator: da técnica à representação. Campinas: Editora da UNICAMP, 2001.

FÉRAL, Josette. Encontros com Ariane Mnouchkine: erguendo um monumento ao efêmero. Tradução de Marcelo Gomes. São Paulo: Senac/Sesc, 2010.

GIL, João Pedro Alcântara. Fragmentos de um Teatro Amoroso. Revista Cena, Porto Alegre, Programa de Pós-graduação em Artes Cênicas, Universidade Federal do Rio Grande do Sul, n. 8, p. 99-111, 2010.

HABEYCHE, Gisela Costa. Caderno de Anotações. Porto Alegre, 2010.

ICLE, Gilberto. Teatro e Construção de Conhecimento. Porto Alegre: Mercado Aberto, 2002.

JAY, Martin. Cantos de Experiencia: variaciones modernas sobre un tema universal. Buenos Aires: Paidós, 2009.

SCHECHNER, Richard. In: BARBA, Eugenio; SAVARESI, Nicola. A Arte Secreta do Ator. São Paulo-Campinas: Editora Hucitec/ Editora da UNICAMP, 1995. P. 203-204.

Ana Cecília de Carvalho Reckziegel é professora da área de atuação teatral no Departamento de Arte Dramática da Universidade Federal do Rio Grande do Sul, atriz-pesquisadora da Usina do Trabalho do Ator. É graduada em teatro, mestre em ciência do movimento e doutoranda no Programa de Pós-Graduação em Educação da Universidade Federal do Rio Grande do Sul. Membro do GETEPE-Grupo de Estudos em Educação, Teatro e Performance.

E-mail: acreckziegel@gmail.com

Gisela Costa Habeyche é professora de voz para teatro no Departamento de Arte Dramática da Universidade Federal do Rio Grande do Sul, atriz-pesquisadora da Usina do Trabalho do Ator. É graduada em teatro, mestre em Educação e doutoranda no Programa de Pós-Graduação em Educação da Universidade Federal do Rio Grande do Sul. Membro do GETEPE-Grupo de Estudos em Educação, Teatro e Performance.

E-mail: gisela.habeyche@gmail.com

Recebido em 14 de março de 2012

Aprovado em 15 de agosto de 2012 